\title{
ON THE POLYMORPHISM OF THE MOTH PANAXIA DOMINULA (L.)
}

\author{
M. H. WILLIAMSON \\ Scottish Marine Biological Association, Oceanographic Laboratory, Edinburgh
}

\section{INTRODUCTION}

Received I5.ii.6o

THERE are as yet remarkably few cases, other than those involving sex or other outbreeding mechanisms, in which the system maintaining a balanced polymorphism is known. My intention in this paper is to show that there is a balanced polymorphism in the colony of Panaxia dominula at Cothill near Oxford, and to make a quantitative examination of the forces that might be maintaining it. I will show that a simple selective force favouring the heterozygote is not an important force in this case, that some of the selective forces discovered by $\mathrm{P}$. M. Sheppard are probably important, and that there are possibly other important selective forces yet to be discovered.

The colony of this day-flying moth near the villages of Cothill and Dry Sandford in Berkshire has been studied every year by E. B. Ford and his associates since 1939. There are three varieties in the colony controlled by a pair of alleles: the common homozygous wild-type dominula, the heterozygote medionigra, and the rare homozygote bimacula. The rarer allele, occuring in medionigra and bimacula, has always been referred to as the medionigra gene. This colony and this segregating locus are very well suited for a study of polymorphism. The colony is isolated from other colonies of the same species, so that only a single population has to be considered. There are but two alleles and all three genotypes can be recognised. The moth is an annual, with a four stage life cycle of egg, larva, pupa and imago, so that there is no overlapping of the same stage of different generations. These last two points make the theoretical analysis the simplest possible. Furthermore, the moth can be bred in the laboratory and new, artificial, colonies can be started.

The history of the colony has been described by Fisher and Ford (1947), and Sheppard (1951, 1953, 1956). For the observations in 1956, r 957 and 1958, which are as yet unpublished but which I have used in my calculations, I am very deeply indebted to Dr E. B. Ford, F.R.s., Dr P. M. Sheppard and Mr L. M. Cook. The main results of this extended study are given in figs. I and 2. The calculated frequency of the medionigra gene (not the genotype) is shown plotted on a logarithmic scale against years in fig. I. Fisher and Ford's value for the gene frequency up to and including 1928 is plotted against 1928 . This value was obtained from studying museum collections, and they argue that it is likely to be higher than the real frequency in 
the colony at that time. For the gene frequencies in 1939 and 1940 I have added the standard errors to the figure, because the sample in I940, II 7 specimens, was much smaller than in any other year. It can be seen that although the gene frequency in I940 was apparently greater than in 1939, it could well have been smaller. The gene frequency declined from 1939 to 1947 , since when it has shown no consistent trend. The estimates for population size, obtained by the method of mark, release and recapture, are shown, again on a logarithmic scale, in fig. 2. The error of each figure, as given in the

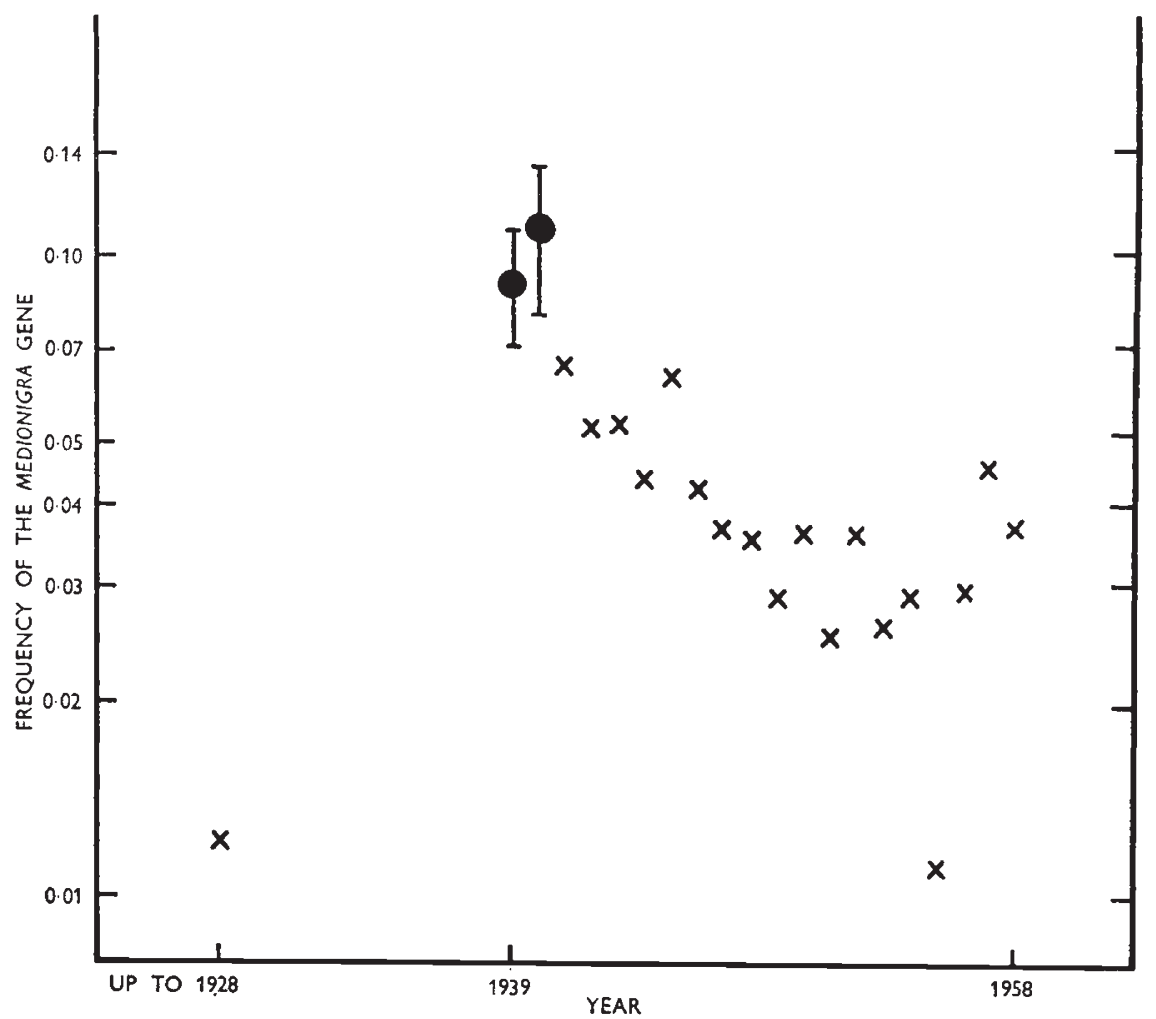

Fig. I. - The estimated frequency of the medionigra gene at Cothill at various times. For 1939 and $194^{\circ}$ the standard error of the estimate is shown.

papers quoted, is also shown. I will refer to the other two lines on this figure towards the end of the paper (p. I50). From I94I, when the first estimate was made, until 1958 there has been an irregular increase in the size of the population, and the regression of population size on years is positive $(\mathrm{P}<0 \cdot 02)$.

As the gene frequency has decreased and the population size increased since the early I940's, it is worth asking whether there is any simple relation between the two. This question has already been asked, and answered in the negative, by Sheppard (I95I). In his fig. 2 he plotted the graphs of change in population size and of 
the apparent selective value of the medionigra genotype. Fig. 3 shows the same graphs with their continuations into the I950's. It is immediately obvious that Sheppard's conclusion was right. There is no simple relation between change in population size and change in gene frequency. The two graphs are out of phase from 1942 to I 948 and in phase from 1949 to 1957 . The graphs give the impression that each tends, independently, to a two year cycle, and if this were

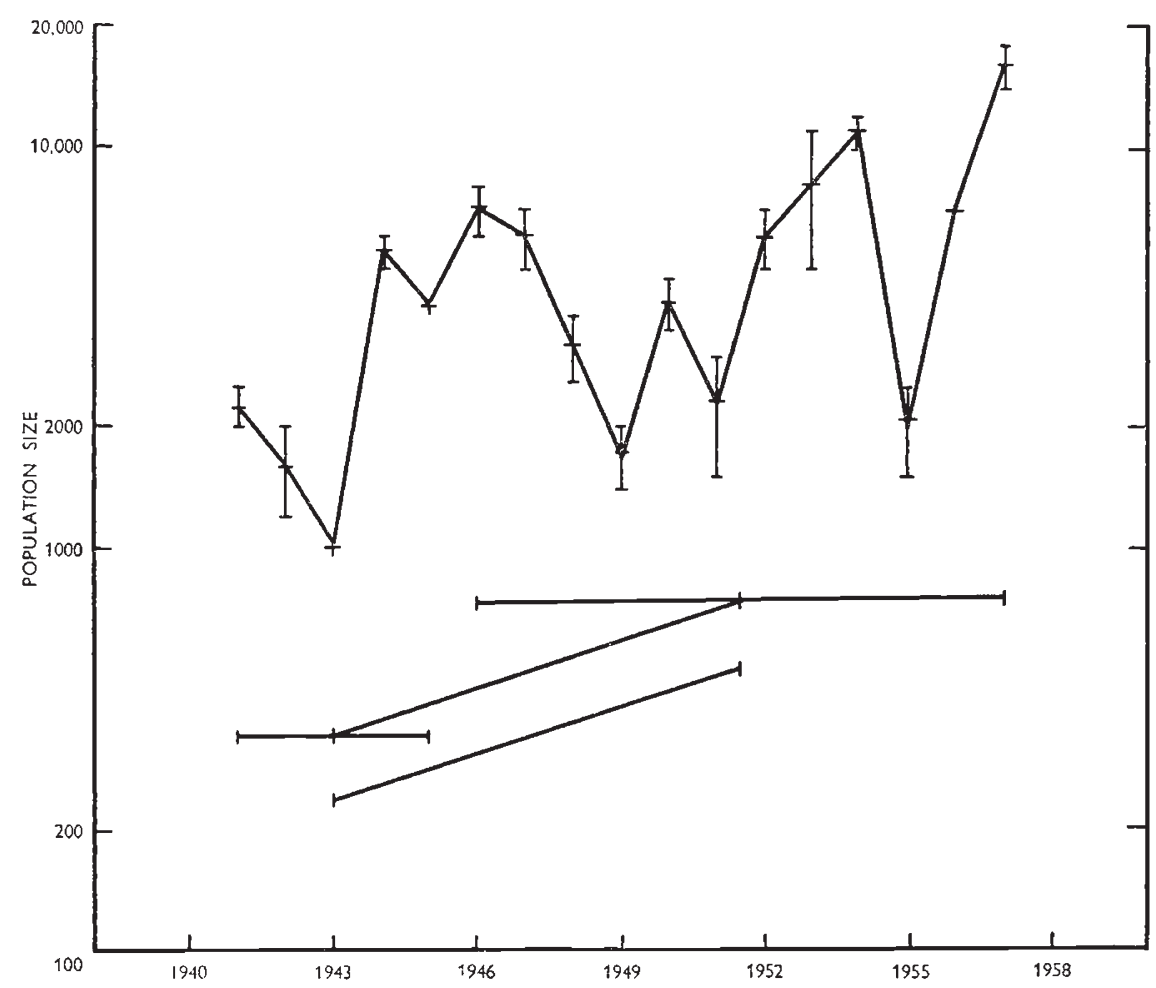

FIG. 2.-Upper graph : Estimates, and estimated error, of the population size of the Cothill colony of Panaxia dominula.

Middle graph : The two population sizes in which one bimacula individual would be expected if the gene frequencies had been at the apparent equilibrium points, for the two periods indicated by the horizontal lines.

Lower graph: The geometrical mean population size $\times \mathbf{1} / \mathbf{1 0}$ for the same two periods.

so, it would explain the existence of an out-of-phase period and an in-phase period. However, I have not been able to convince myself that the graphs show more turning points, more maxima and minima, than would be expected in a random series.

Three points are needed for the detection of a turning point. The question is what is the probability, in a random series, that the middle point of any set of three will be a turning point ? One can argue that the second point has equal chances of being greater or smaller than the first, and the third equal chances of being greater 
or smaller than the second. Then the probability of the second being a turning point is one half. On this criterion, both graphs of fig. 3

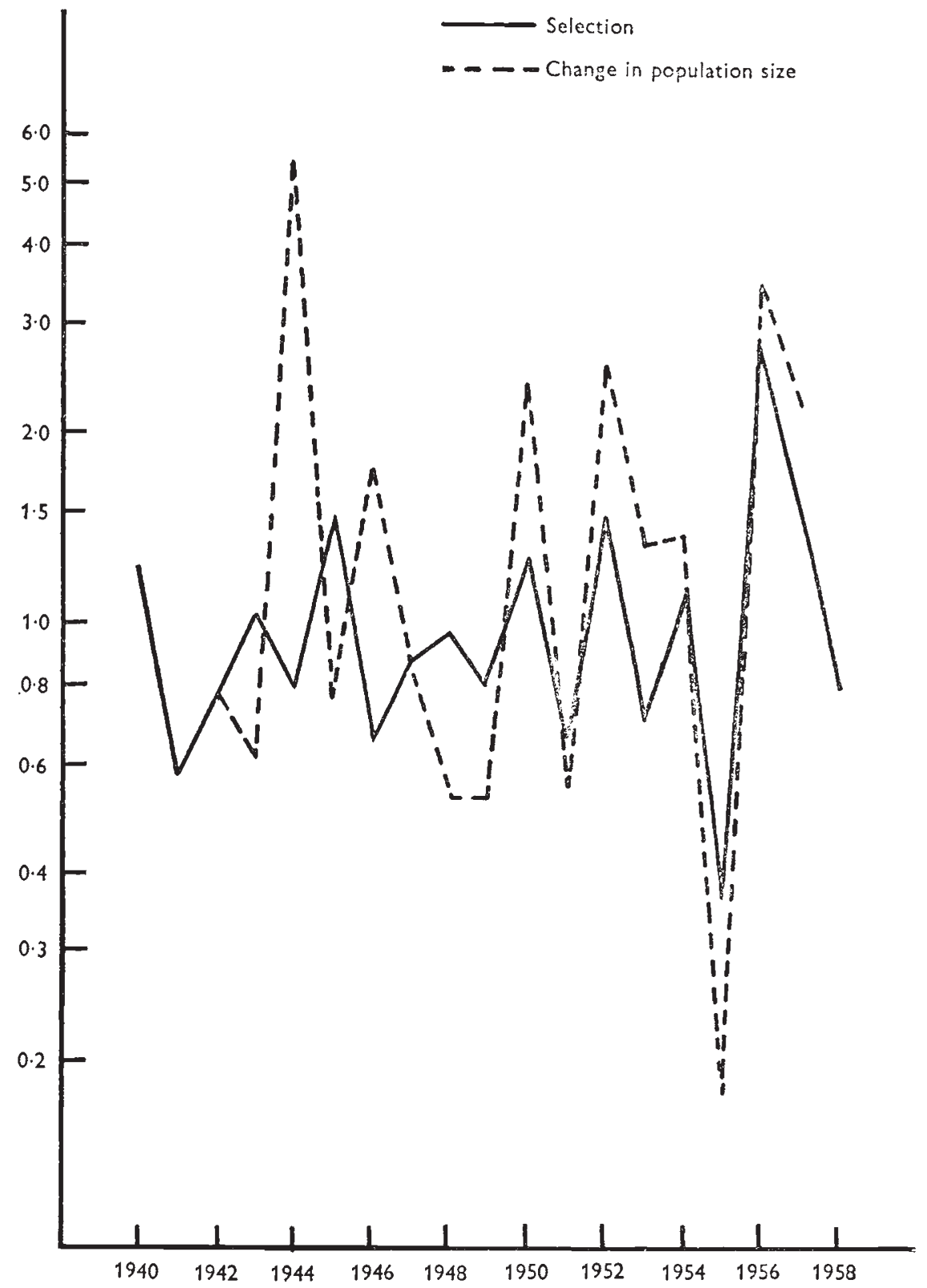

FIG. 3.-Continuous line: Apparent selective value of the medionigra genotype. Dashed line : Change in the population size.

have too many turning points, that of apparent selective value having a probability of less than I per cent. of being a random series, that of change of population size a probability of less than 5 per cent. 
On the other hand one can argue that taking three different numbers in all their six possible arrangements, four of these have turning points, so that the expected frequency of turning points in a random series is two-thirds (Cole, I954). If this is accepted, both the graphs in fig. 3 could be random series. A more refined test for non-randomness is to calculate the first serial correlation coefficients. Neither of these is significant, though that for apparent selection, $r_{1}=-0.4 \mathrm{I}$ with $I_{5}$ degrees of freedom, has a probability of less than ro per cent. So while these series may be oscillating series, it is not yet possible to prove this.

\section{SOME POINTS OF THEORY}

The analysis of the changes in gene frequency will be more easily followed if some points in the theory of polymorphism are considered first. Even the simplest polymorphism, involving only two alleles at one locus in a population with discrete generations, can be maintained in a great variety of ways. I have listed (Williamson, 1958) the systems which are known to be capable of producing polymorphisms: here I will give a reduced, and rather different, classification of those which can act in the simplest polymorphism, such as that found in Panaxia. These systems can be grouped into four categories, the first two involving but a single selective force, the last two needing more than one force.

In category one there is a single, constant, selective force, and for this to produce a balanced polymorphism it must favour the heterozygote. It is perhaps worth pointing out that the definition of a constant selective force is arbitrary, and one could define it in such a way that the conventionally accepted constant value was a variable value. In a polymorphism maintained by selection for the heterozygote, there will be more heterozygotes in the population than would be expected from the Hardy-Weinberg ratios; but the converse is not true. In a simple sex dimorphism with $5^{\circ}$ per cent. males and 50 per cent. females, the frequency of the $\mathrm{Y}$ chromosome is 25 per cent., so the expected frequency under random mating of $\mathrm{XY}$ heterozygotes is $37 \frac{1}{2}$ per cent., against the $5^{\circ}$ per cent. observed. To show an excess of heterozygotes in a population shows neither that there is a balanced polymorphism nor, if there is one, how it is maintained. Conversely, in many cases the excess expected is small, so small that it might not be possible to demonstrate it in some natural population.

Category two includes balanced polymorphisms maintained by a single variable selective force. Examples are non-random mating, including sex, and cases where selection is a function of gene frequency, or gene number, or a function varying in space or time. Members of this category come under the heading B of Williamson (1958).

Members of category three can be called secondary polymorphisms. In them selective forces produce a polymorphism only because some other 
selective force has already produced another balanced polymorphism. This category includes cases depending on sex dimorphism, linkage and sex-linkage; they come under the heading $\mathrm{A}_{3}$ in Williamson (1958).

Category four is in my opinion the only category to which the expression " balance of selective forces" is appropriate, and it includes all those cases in which two or more biologically distinct selective forces interact to give a balanced polymorphism. An example is the polymorphism of the $t$ locus in mice (Dunn, 1957). As will be seen, the polymorphism of Panaxia dominula probably falls here.

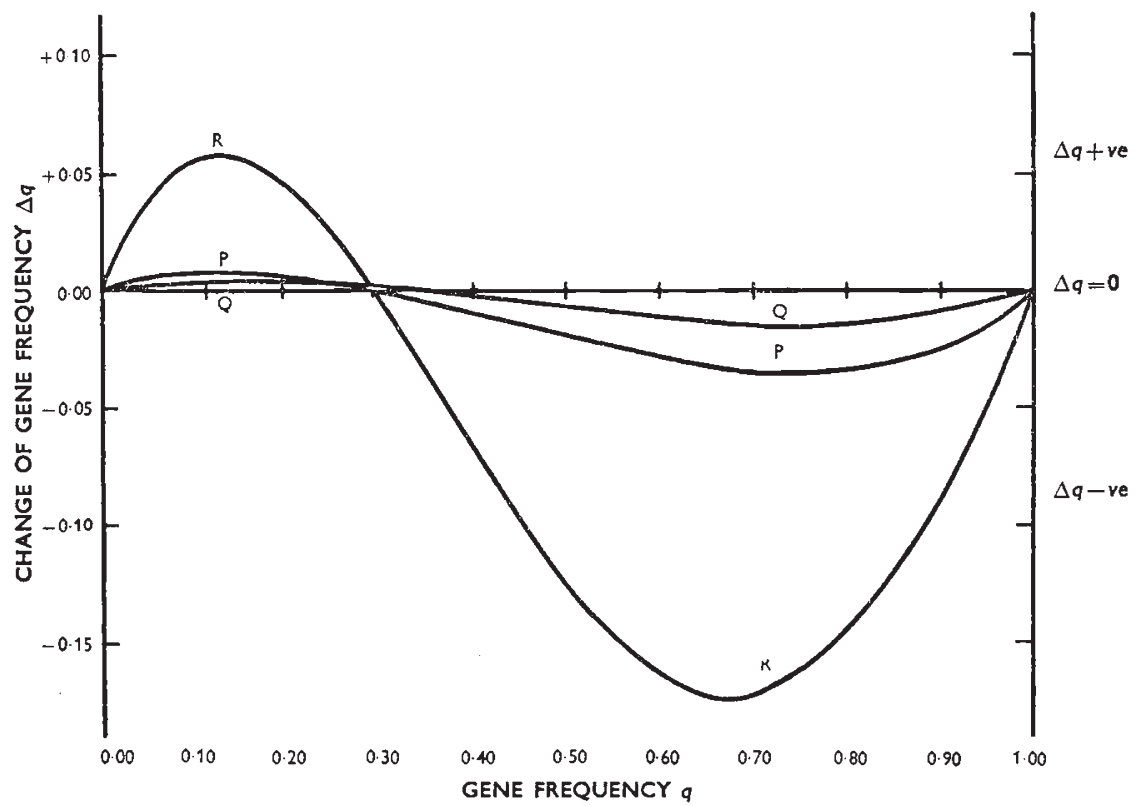

Frg. 4.-Curves of change in gene frequency $(\Delta q)$ against gene frequency $(q)$ for three balanced polymorphisms. The equations of the curves are

$$
\begin{aligned}
& \mathrm{P}: \Delta q=\left(2 q-9 q^{2}+7 q^{3}\right) /\left(18+4 q-7 q^{2}\right) \\
& \mathrm{Q}: \Delta q=\left(q-4 q^{2}+3 q^{3}\right) /\left(\mathrm{r} 8-3 q^{2}\right) \\
& \mathrm{R}: \Delta q=q-5 q^{2}+6 q^{3}-2 q^{4}
\end{aligned}
$$

Note the difference in the scales along the $\Delta q$ and $q$ axes.

Consider the change of gene frequency to be expected in a polymorphic population, of any of the categories listed above, when the gene frequency is not the equilibrium frequency. As a population with discrete generations has been postulated, the changes in gene frequency will also be discrete, and the frequencies can be arranged in a chain, $q_{1}, q_{2}, q_{3} \ldots$. Unless the selective force is of a special type, the change from $q_{i+1}$ to $q_{i+2}$ will be independent of $q_{i}$, and, in general, given $q_{i+1}, q_{i+2}$ will not be determined exactly but will have a probability distribution. In other words, the chain of $q$ 's will be a stochastic Markov process. If the selective forces involved and the initial gene frequency, $q_{1}$, were known, one might still find a significantly bad fit between the theoretical and observed curves starting at $q_{1}$, if, for instance, the first step from $q_{1}$ to $q_{2}$ happened to be a rather improbable 
one. An analysis of a polymorphism by examining the curve of gene frequency against time can be misleading. A better method of analysis is to examine the change in gene frequency, $\Delta q_{i}$, against gene frequency $q_{i}$, where $\Delta q_{i}=q_{i+1}-q_{i}$. The probability distribution of $\Delta q_{i}$ depends on $q_{i}$ and not on $q_{i+1}$, and so the correct plot is of $\Delta q_{i}$ against $q_{i}$.

The theoretical curves for $\Delta q$ against $q$ for three balanced polymorphisms are shown in fig. 4. Each system has selective forces of roughly the same intensity, and each has approximately the same equilibrium point. Near the equilibrium point, the curves are

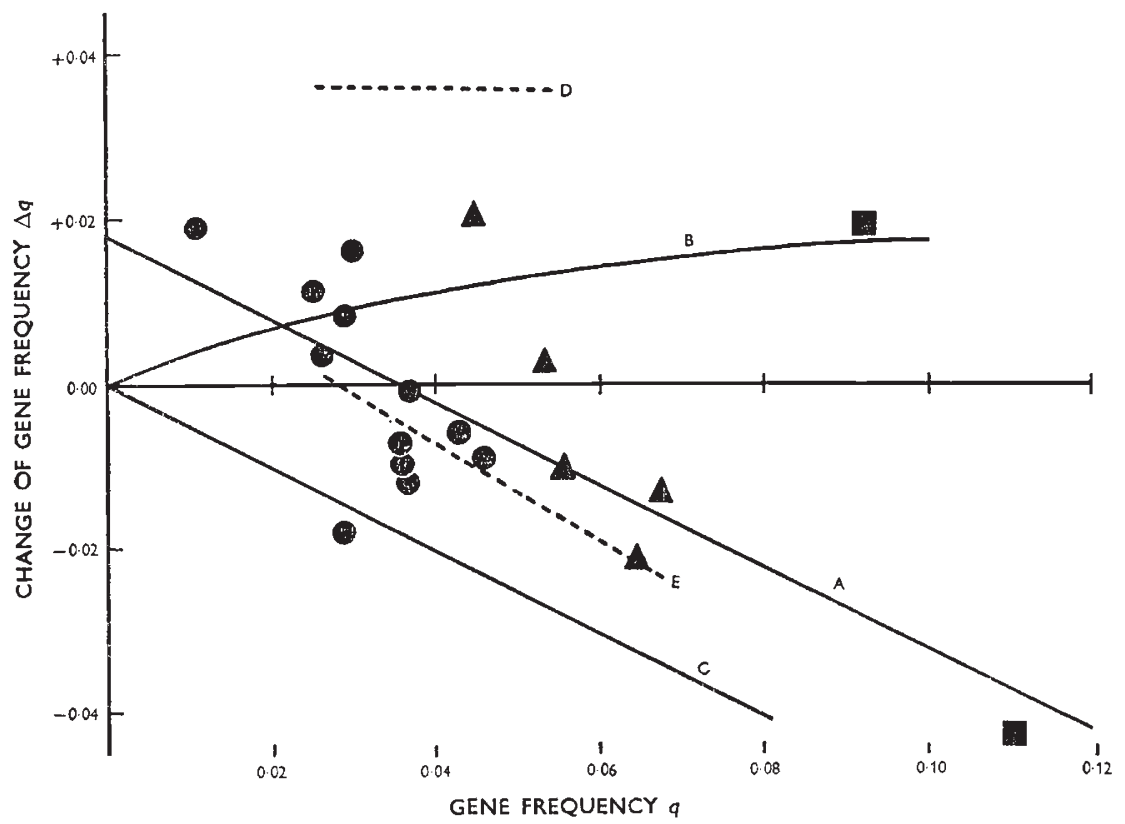

FIG. 5.-The observed values of gene frequency plotted against the changes from those

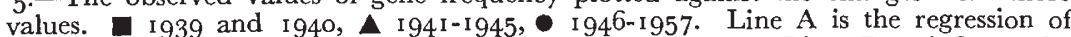
change of gene frequency on gene frequency for $194^{1-1}-1957$. Lines B and $\mathrm{C}$ are the changes expected for Sheppard's values for non-random mating and fertility and his value for larval mortality, respectively. Lines $\mathrm{D}$ and $\mathrm{E}$ are the lines needed to produce, in conjunction respectively with $\mathrm{G}$ and $\mathrm{B}$, line $\mathrm{A}$.

approximately straight, and, as Lewontin (1958) points out, all necessarily have a negative slope. Curve $\mathrm{P}$ is a polymorphism of category one, $\mathrm{Q}$ of category three and $\mathrm{R}$ of category two. $\mathrm{R}$ involves non-random mating, and its slope is much greater than those of the other two curves. If the slope of a curve near the equilibrium point is greater than minus one, the gene frequency will oscillate around the equilibrium point. In Panaxia there is a possibility of such an oscillation, and so the possibility of such a steep curve.

\section{THE CHANGES OF GENE FREQUENCY AT COTHILL}

From the values used in fig. I it is easy to construct fig. 5, which shows $\Delta q_{i}$ plotted against $q_{i}$, and some calculated curves which will be explained in due course. Three symbols have been used for the 
points; the two squares on the right refer to the gene frequencies of I939 and I940, the triangles in the middle to years I94I-45, and the circles to $1946-57$. The general scatter of the points suggests a balanced polymorphism, $\Delta q$ being positive for very small $q$ and negative for larger values. As was pointed out in the introduction, the gene frequency was determined less exactly in 1940 than in the other years, so that the two square points in fig. 5 are unreliable, and have not been used in the calculations. The use of extreme values that are not reliable could easily lead to misleading results, though in this case it can be seen that they would not have an overwhelming effect. The correlation of $\Delta q$ with $q$ using all nineteen points is $-0.489(p<0.05)$; with seventeen points, eliminating the two square ones, it is $-0.572(p<0.02)$. These values show, at least to the extent to which they are significant, that there are non-random forces acting. As the population is a closed one, this means that there are appreciable selective forces and that there is a balanced polymorphism. There is a suggestion in fig. 5 that the equilibrium gene frequency was higher, about 5.5 per cent., in $\mathrm{I} 94 \mathrm{I}-45$ than in the years since. I will return to this point, but for the time being I will treat the years I $94 \mathrm{I}^{-5} 5^{8}$ as a homogeneous set.

Before trying to fit any theoretical curves to fig. 5 , it is convenient to calculate a line from the points. Both $q$ and $\Delta q$ are subject to error and Moran (1956) has pointed out that in such a case, using only second degree statistics, any line between the regression of $q$ on $\Delta q$ and the regression of $\Delta q$ on $q$ can be fitted to the data. The shallowest of these is the regression of $\Delta q$ on $q$, and this is a fairly satisfactory line in that it assumes that the estimate of $q$ is free from error and that all the error is in $\Delta q$, and $\Delta q$, being based on pairs of $q$ values, will in fact be more subject to error than $q$. This regression line is shown on fig. 5 and is labelled A. Its slope is -0.496 , or very nearly minus one-half. This is the shallowest line that can reasonably be fitted to the points; as will be seen, it is quite hard to find a theoretical curve to match this. Another obviously possible and rather steeper line is the reduced major axis (Kermack and Haldane, I950). The slope of this is -0.868. This is still less than minus one, so again it seems unlikely that the selective system leads to an oscillation, even a damped oscillation, around the equilibrium gene frequency. For the moment, I will only attempt to match line A, and not any steeper one.

Three conclusions, all rather negative, can be drawn from the position and slope of line A. The first is that the equilibrium gene frequency, which is now at least 3.5 per cent. of the allele for medionigra, is greater than the frequency observed up to I928. That frequency was I. 2 per cent. with fiducial limits of $2 \cdot 6$ per cent. and $3 \cdot 2$ per cent. at the 5 per cent. and I per cent. significance levels. Dr H. B. D. Kettlewell tells me that medionigra taken up to I 928 were not as easily distinguished from the wild-type dominula as modern medionigra. It 
is in any case evident from fig. I that some very remarkable event took place at Cothill between I928 and i939. The second conclusion is that selection against the rare homozygote bimacula can be ignored. The equilibrium gene frequency $q$ is so low that eliminating all bimacula, which would have a frequency of about $q^{2}$, would affect $q$ to an extent that is negligible compared with the effect indicated by line A.

The third conclusion is that selection favouring the heterozygote is not the principal cause of the polymorphism; the polymorphism does not belong to category one. Suppose that the polymorphism is of category one, and that the selective values of dominula, medionigra and bimacula are $\mathrm{I}-s$, I and $\mathrm{I}-t$, and that the equilibrium gene frequency is $0 \cdot 035$. Then $t$ will be greater than $s$, but for any value of $t$ a value of $s$ can be found that will give an equilibrium of 0.035 . However, $t$ cannot exceed one, and with that value the curve of $\Delta q$ against $q$ will be as steep as can be achieved with this system of maintaining a polymorphism. It is well known that in this system the equilibrium frequency $\hat{q}=s /(s+t)$, and with $\hat{q}=0.035, t=\mathrm{I}$ we get $s=0.036$. It can be shown that, at $\hat{q}, d \Delta q / d q=-s t /(s-s t+t)$ and in this case this gives a slope of $-s$ or -0.036 for the slope at $\hat{q}$ of the curve relating $\Delta q$ to $q$. This is less than one-tenth of the slope of line $\mathrm{A}$, and it is evident that the change in gene frequency under a polymorphism of category one would be much too slow to account for the changes observed in the population of Panaxia dominula at Cothill.

Having eliminated some possibilities, one can now examine the selective forces found by Sheppard (1952, I953), and see if they are sufficient to account for the polymorphism. He found four types of selection. The first was that bimacula had the marks of birds' beaks on its wings much more frequently than either medionigra or dominula. Considering the known lethargy and comparative lack of protective colouring of bimacula this observation probably, though not necessarily, means bird predation is a selective force acting against bimacula. I have already shown that such a selective force can be ignored.

Sheppard started an artificial colony with backcross broods of medionigra $\times$ dominula, and recovered thirty pupæ of which twenty-one were dominula. This suggests that the survival of eggs and larvæ of medionigra is only about 50 per cent. of the survival of dominula, and if this is really so it would lead to the change of gene frequency indicated by the line $\mathrm{G}$ in fig. 5. Nothing is known of the possible selection on the young stages of bimacula, so not much reliance could be placed on the line $\mathrm{C}$ even if it were based on more extensive experiments with dominula and medionigra. Nevertheless, some strong selection approximating to that indicated by $\mathrm{C}$ will be needed to produce the steep downward slope of A.

The third and fourth types of selection found by Sheppard relate to the mating and fertility of imagoes. His experiments showed that 
medionigra males are less fertile than dominula and possibly also than bimacula males. He also showed that dominula prefers to mate with medionigra rather than dominula, though medionigra when given a choice of medionigra and dominula showed no preference. In experiments with medionigra and bimacula each showed a strong preference for the other. Haldane (I954) found no evidence for mating preference in the wild, but his test was based on the assumption that there were no other selective forces. As these exist and seem to be strong, his test is not valid, and there is no reason for not using Sheppard's results.

It is convenient to combine both their last two sorts of selection in a matrix of the form I have developed (Williamson, I959), but before this can be done it is necessary to decide on numerical values for the forces. A variety of figures could be taken from Sheppard's results, so I have chosen round numbers close to his mean values. I have though it best to ignore the results with bimacula, as it would be necessary to invent a figure for its like or dislike of dominula as a mate and as it seems rather inconsistent that male medionigra should be less fertile than male bimacula. Leaving bimacula out of the equations avoids the necessity of coming to a decision on these points, and by restricting attention to gene frequencies near the equilibrium point, one can expect that ignoring bimacula will not lead to gross errors. For the other values, I have assumed that dominula prefers medionigra to dominula in the ratio of two to one, and that the fertility of medionigra is 75 per cent. of that of dominula.

The random mating matrix in Williamson (1959) has the form

$$
\left[\begin{array}{ccc}
d+h & \frac{1}{2}(d+h) & 0 \\
r+h & \frac{1}{2}(d+2 h+r) & d+h \\
o & \frac{1}{2}(r+h) & r+h
\end{array}\right] \quad\left[\begin{array}{c}
d \\
2 h \\
r
\end{array}\right]
$$

where $d, 2 h$ and $r$ are the frequencies of one homozygote, the heterozygote and the other homozygote, and $d+2 h+r=\mathrm{I}$. Adapting this to the non-random mating and infertility of Panaxia gives

$$
\left[\begin{array}{ccc}
\frac{d+2 h}{d+4 h} \frac{3}{4} \cdot \frac{(d+h)}{2} & - \\
\frac{2 h}{d+4 h} \frac{3}{4} \cdot \frac{(d+h)}{2} & - \\
0 & \frac{3}{4} \cdot \frac{h}{2} & -
\end{array}\right]\left[\begin{array}{c}
d \\
2 h \\
-
\end{array}\right]
$$

with $d+2 h=\mathrm{I}$. Manipulation of the matrix, and noting that in this case $h=q$, gives the following formula for the change in gene frequency

$$
\Delta q=\frac{3 q-\mathrm{I} 6 q^{2}+20 q^{3}}{8+\mathrm{I} 2 q-8 q^{2}}
$$


The graph of this equation is shown in fig. 5 and is labelled B. It is likely that the curve B should, if anything, be higher; that is, the value for $\Delta q$ for any $q$ should be greater than that indicated. This is because Sheppard's experiments suggest that bimacula is both more fertile and has a greater effect on mating preference than medionigra, and both these effects would move B higher.

For two selective forces to produce a polymorphism of category four, the curves of their equations for $\Delta q$ against $q$ must be of different shapes so that their resultants resemble the curves of fig. 4. Curves of the types of $\mathrm{B}$ and $\mathrm{C}$ in fig. 5 are one of the possible pairs of types to do this. B rises more sharply at first and then flattens out, $\mathrm{C}$ falls steadily, so that it would be possible at low $q$ that $\mathrm{B}$ would be greater than $\mathrm{C}$, so that the resultant $\Delta q$ was positive, and that at higher values of $q \mathrm{C}$ would be greater than $\mathrm{B}$, and so $\Delta q$ would be negative. Unfortunately $\mathrm{B}$ rises too slowly, or alternatively $\mathrm{C}$ falls too fast, for them to produce an equilibrium; the resultant $\Delta q$ is negative for all $q$. The curves which would complement $\mathrm{B}$ and $\mathrm{C}$ to produce $\mathrm{A}$ in the region of the equilibrium frequency are also shown in fig. 5 . They are labelled $\mathrm{E}$ and $\mathrm{D}$ respectively. That $\mathrm{D}$ runs at such a high value of $\Delta q$ and $\mathrm{E}$ is so close to $\mathrm{A}$ are consequences of the order of events in the Panaxia life cycle. This order is: gene frequency observed, selection types three and four (mating preference and fertility, curve B), selection type two (juvenile mortality, line C), next observation of gene frequency. As selection types three and four increase the gene frequency, selection type two acts on a higher gene frequency than they do. The inverse of line B will necessarily be closer to the abscissa than is B.

Sheppard has found selective forces of the right type to produce a polymorphism of category four. The values he has found for the strength of these forces would not in fact produce a polymorphism, but as his values are subject to large experimental errors this is not particularly disturbing. If, on the other hand, his values are well determined, some other selective force, as yet unknown, is needed to produce the observed balanced polymorphism.

It might be as well to leave this study at that point, but there is still one topic that should be discussed, as it requires investigation. That is the question of whether or not there have been, since r $94 \mathrm{I}$, two points of equilibrium, and two curves of $\Delta q$ against $q$, one fitting the triangles of fig. $5(194-45)$ and one the circles (1946-57). As this possibility is suggested by fig. 5 it cannot be tested by the values plotted there. If these two curves have existed, each would be much steeper than curve A, and each would possibly represent an oscillating system. It is quite possible that such a system exists in Panaxia. For the two periods involved one can calculate the geometric mean population size, and also that population size which would have an expectation of producing exactly one bimacula at the apparent equilibrium gene frequency for the period. These two pairs of values 
have been calculated and plotted on fig. 2, the geometric means being plotted at one-tenth of their values to avoid confusion with the main curve. The resemblance of the two slopes is interesting: I think it not wise to speculate on any possible meaning of this resemblance. I would just suggest that more mating preference experiments should be done with bimacula, possibly using more than three moths at a time.

The colony of Panaxia dominula at Cothill has probably been studied for longer, and more intensively, than any other population of any organism, yet more experiments will be needed before the genetical system of the population is understood. I hope that this paper will be found useful both in showing the present state of knowledge and in indicating what further experiments might be tried.

\section{SUMMARY}

I. The intention of the paper is to show that there is a balanced polymorphism in the Cothill population of Panaxia dominula, and to make a quantitative examination of the forces that might be maintaining it.

2. Graphs are given showing the gene frequency up to $195^{8}$ and the population size up to 1957 .

3. The possibility that both the apparent selection against the medionigra genotype and the change in population size oscillate with a period of two years is examined.

4. The mechanisms that can maintain a balanced polymorphism with two alleles in a population with discrete generations are classified into four categories.

5. Reasons are given for examining such polymorphisms with the use of a plot of the change in gene frequency $\Delta q_{i}$ against gene frequency $q_{i}$.

6. The curve of $\Delta q$ against $q$ for the Cothill data has a slope of about $-\frac{1}{2}$ or steeper, and the equilibrium gene frequency is at about $3 \frac{1}{2}$ per cent.

7. No polymorphism maintained by selection for the heterozygote could give such a steep curve at so low an equilibrium point.

8. The interaction of the selective forces found by Sheppard could give such a curve, though his estimates do not in fact give a curve fitting the observed curve.

9. The possibilities that there has been more than one equilibrium point, that the polymorphic system is an oscillating one, and that there is some relation between these and both population size and the occurrence of a few bimacula in the population are briefly mentioned.

Acknowledgments.-I am greatly indebted to Dr E. B. Ford, F.R.s. for allowing me to use his unpublished results and for his helpful comments on the manuscript. I am very grateful to Dr P. M. Sheppard for the many useful discussions I have 
had with him, for his helpful criticism of the manuscript, for supplying data and for introducing me to experiments with beads. I would also like to thank Dr H. B. D. Kettlewell and Mr L. M. Cook for their comments and information.

\section{REFERENCES}

COLE, L. C. 1954. Some features of random population cycles. F. Wildlife Management, $18,2-24$.

DUNN, L. C. 1957. Evidence of evolutionary forces leading to the spread of lethal genes in wild populations of house mice. Proc. Nat. Acad. Sci., 43, 158-163.

FISHER, R. A., AND FORD, E. B. I947. The spread of a gene in natural conditions in a colony of the moth Panaxia dominula L. Heredity, $x, \mathrm{I} 43^{-1} \mathrm{I} 74$.

haldane, J. в. s. 1954. An exact test for randomness of mating. F. Genet., 52, $63 \mathrm{I}-635$.

KERMACK, K. A., AND HALDANE, J. B. S. I950. Organic correlation and allometry. Biometrika, 37, 30-4I.

LEWONTIN, R. C. 1958. A general method for investigating the equilibrium of gene frequency in a population. Genetics, 43, 419-434.

MORAN, P. A. P. I956. A test of significance for an unidentifiable relation. $\mathcal{F} . R$. Statist. Soc. B, 18, 6r -64 .

SHEPPARD, P. M. I951. A quantitative study of two populations of the moth Panaxia dominula (L.). Heredity, 5, 349-378.

SHEPPARD, P. M. 1952. A note on non-random mating in the moth Panaxia dominula (L.). Heredity, 6, 239-241.

Sheppard, P. м. 1953. Polymorphism and population studies. Symp. Soc. Exp. Biol., 7, 274-289.

SHEPPARD, P. M. I956. Ecology and its bearing on population genetics. Proc. Roy. Soc. B, 145, 308-315.

williamson, м. н. 1958. Selection, controlling factors and polymorphism. Amer. Nat., 92, 329-335.

Williamson, M. H. 1959. Some extensions of the use of matrices in population theory. Bull. Math. Biophys., 21, I3-1 7 . 